Article

\title{
Assessment of the Benefits of Information and Communication Technologies (ICT) Adoption on Downstream Supply Chain Performance of the Retail Industry
}

\author{
Kedar Shiralkar ${ }^{1}$, Arunkumar Bongale $\left.{ }^{1, *} \mathbb{(}\right)$, Satish Kumar ${ }^{1,2}\left(\mathbb{D}\right.$, Ketan Kotecha ${ }^{2}\left(\mathbb{D}\right.$ and Chander Prakash ${ }^{3}(\mathbb{D})$ \\ 1 Symbiosis Institute of Technology, Symbiosis International (Deemed University), Lavale, \\ Pune 412115, Maharashtra, India; kedar.shiralkar.phd2019@sitpune.edu.in (K.S.); \\ satishkumar.vc@gmail.com (S.K.) \\ 2 Symbiosis Centre for Applied Artificial Intelligence, Symbiosis International (Deemed University), Lavale, \\ Pune 412115, Maharashtra, India; director@sitpune.edu.in \\ 3 School of Mechanical Engineering, Lovely Professional University, Phagwara 144001, India; \\ chander.mechengg@gmail.com \\ * Correspondence: arun.bongale@sitpune.edu.in
}

check for updates

Citation: Shiralkar, K.; Bongale, A.; Kumar, S.; Kotecha, K.; Prakash, C. Assessment of the Benefits of Information and Communication Technologies (ICT) Adoption on Downstream Supply Chain Performance of the Retail Industry. Logistics 2021, 5, 80. https://doi.org/ $10.3390 /$ logistics 5040080

Academic Editor: Robert Handfield

Received: 20 August 2021

Accepted: 5 November 2021

Published: 10 November 2021

Publisher's Note: MDPI stays neutral with regard to jurisdictional claims in published maps and institutional affiliations.

Copyright: (c) 2021 by the authors. Licensee MDPI, Basel, Switzerland. This article is an open access article distributed under the terms and conditions of the Creative Commons Attribution (CC BY) license (https:// creativecommons.org/licenses/by/ $4.0 /)$.

\begin{abstract}
Background: The COVID-19 pandemic-driven supply chain disruptions have pushed supply chain decision-makers in the retail industry to implement information and communication technologies (ICT) to improve the efficiency and resiliency of their supply chain. However, they need some guidance to identify the functional elements of the supply chain for ICT adoption and the benefits of implementing ICT on their supply chain performance. Methods: We conducted an empirical study that provides guidance on the performance benefits of ICT adoption specifically for the downstream supply chain of the retail industry. This study employed the feature engineering technique to prioritize the functional elements of the supply chain to maximize the benefits of ICT adoption on supply chain performance. Results: ICT adoption benefits the retail industry's overall downstream supply chain performance in the range of $9-41 \%$. Moreover, the study discovered the key functional elements of the supply chain for ICT adoption that significantly improve the overall supply chain performance. Conclusions: The study presents a definite view of the quantitative benefits of ICT adoption to the supply chain decision-makers of the retail industry and aids them in selecting appropriate functional elements for ICT adoption to maximize their supply chain performance.
\end{abstract}

Keywords: supply chain in the retail industry; supply chain functional elements; ICT adoption; feature selection; feature engineering

\section{Introduction}

Post-COVID-19 pandemic, retail supply chains are grappling with dynamic and operational changes and challenges in real time, causing significant supply chain disruptions [1]. Hence, supply chain leaders are considering adopting information and communication technologies (ICT) to mitigate short-term consequences and effectively design long-term strategies to make their supply chains profitable and resilient against future disruptions. According to Gartner's research, ICT adoption in the supply chain results in substantial revenue growth, and cloud offerings in the supply chain are driving this growth significantly [2]. Thus, ICT has proven to be a boon for both firms and supply chain partners to coordinate supply chains transparently and to make supply chains more resilient to disruptions. ICT in the retail supply chain enables collaboration and the exchange of quality information between a firm and its supply chain partners, empowering efficient supply chain operations that positively contribute to the firm's competitiveness [3].

In the era of market globalization, information management is vital for the effective selection and management of supply chain partners spread across different geographies. 
However, the globalization of the supply chain partner base generates barriers in integrating and sharing information due to organizational, legal, collaborative, and informational challenges [4]. Therefore, it is imperative to obtain well-designed information systems that effectively handle information resources for cost reductions and to meet legal and organizational compliances more effectively [5].

Well-designed ERP systems significantly improve the integration of internal business processes, ensure better information flow between supply chain members, and thus helps to improve the collaboration and relationships between them [6]. IoT and AI-based technologies provide a prediction of supply chain partners' capabilities more quickly, enabling decision making in real time and thus significantly improving retail supply chain performance [7]. An integrated IT platform supporting the roll-out of various solutions enables firms to keep pace with the development of new functionalities more quickly, improving supply chain responsiveness and business continuity and introducing agility into the supply chain.

Thus, the scope of ICT adoption in various supply chain business functions is extensive and literally touches all the intricacies involved in the coordination of the supply chain. Therefore, the effect of ICT adoption on the supply chain performance needs to be estimated by analyzing its impact on various functional elements of the supply chain. Hence, this study aims to empirically assess how ICT adoption in different functional elements of the retail supply chain helps to optimize its overall performance.

\section{Literature Review}

The objective of this literature review is to gain knowledge about the various functional elements of the supply chain and how ICT adoption in these functional elements influences overall retail supply chain performance.

Information sharing is critical for supply chain success. Two crucial aspects of information sharing are connectivity and willingness. Both these aspects are essential to improve operational performance and to build actual information sharing capabilities [8]. The use of ICT in information sharing supports information use and thus helps to build willingness among supply chain partners to participate in information sharing [9]. ICT-enabled information sharing ensures that consistent and accurate information is transmitted among supply chain partners, leading to better predictability of demands; thus, ICT-enabled information sharing provides a cost advantage by optimizing the inventory at each stage of the supply chain [10].

Fundamentally for supply chain partners, quality of information leads to a reduction of the risk associated with demand uncertainty [11]. ICT improves information quality by presenting a single truth of data from heterogeneous data sources within the supply chain ecosystem, building trust among chain participants. Thus, information quality aids in creating a shared vision and developing strategic relationships among supply members to improve supply chain resilience [12,13].

With a tightly integrated supply chain, knowledge and information flow among participants more effectively and become significant production resources. However, this creates more incidences of information leakage and knowledge leakage [14]. Thus, privacy becomes an important concern when sharing sensitive information [15]. Hence, there is a need for a trusted network between supply chain participants to build information privacy [16]. The secure usage of information is essential to improve trust, transparency, and information disclosure between supply chain participants. ICT acts as a distributed ledger and ensures supply chain transactions are shared openly while ensuring confidentiality, stability, and security by ensuring data privacy during sharing $[17,18]$. 
The standardization of information, processes, and practices in supply chain operations is critical to improve supplier relationships and to reduce risk and uncertainty in a supply chain, and thus requires compatibility and interoperability in the supply chain [19]. Modern supply chain Software-as-a-Service (SaaS) platforms provide features to enable the integration of different platforms of the supply chain ecosystem. These platforms also provide the capability to define standard business rules for supply chain processes and expose enterprise information in familiar business terms to meet compatibility and interoperability needs [20].

The retail supply chain presents operational challenges due to turbulent and volatile environmental conditions [21]. Supply chains need to respond to fluctuating customer demands and to provide a faster response time to customer requests [22]. Thus, supply chains need to be agile to make timely decisions and bring operational flexibility through effective joint planning and partnership building [23]. ICT improves supply chain agility by streamlining changes resulting from demand uncertainty [24,25]. Virtual supply chains enabled with IoT and sensors also help supply chain participants to coordinate from any location, which introduces agility into supply chains [26].

Traceability is crucial in the supply chain to minimize losses due to theft or the misplacement of raw materials and finished goods. ERP and RFID technology enhance material flow and reduce losses due to theft or misplacement [6]. Thus, the benefits of using ICT for traceability are manifold, ranging from safety to risk management, efficiency, compliance, and sustainability goals.

Supply chain integration connects people, processes, and products, thus helping firms to improve operational performance in terms of cost and better utilization of resources, leading to enhanced business profit [27]. Robust supply chain integration improves logistical performance significantly [28]. Cloud-enabled supply chain integrations provide sustainability and reduce firms' investment in managing infrastructure resources, reducing the total cost of ownership [29]. Block-chain-enabled supply chains prove to be more business-compliant and sustainable [30]. Thus, supply chain integration using modern technologies is crucial to improve overall supply chain performance.

Financing is vital for supply chain coordination through cash flow optimization [31]. AI-driven supply chain finance solutions assesses the supplier's risk aversion attitude by considering its financial strength and recommends an appropriate payment solution to the supplier to minimize financial flow risk [32]. E-invoicing and payment systems ensure security, convenience, and privacy during financial transactions, leading to trust among supply chain members [33].

Firms use supply chain audits to determine the supplier's reliability for customizing contract offerings to lower supply risk [34]. Furthermore, they employ change management practices to re-engineer the supply chain to build a resilient system to avoid future disruptions and manage supply chain risks [35]. Thus, compliance is a crucial functional element because it involves implementing auditing and change management practices for risk identification, analysis, and management in each stage of a supply chain to reduce supply chain vulnerabilities [36]. The combination of IoT and blockchain technologies provides effective auditing of information flow and physical material movement, thus enabling firms to have better administrative control over their supply chains [37].

The above discussion implies nine functional elements of the supply chain, and ICT adoption in these elements influences supply chain performance. Table 1 summarizes these functional elements of supply chains. 
Table 1. Summary of functional elements in supply chains.

\begin{tabular}{cl}
\hline Functional Element Name & \multicolumn{1}{c}{ Description } \\
\hline Information Quality & $\begin{array}{l}\text { Refers to various constructs such as reliability, } \\
\text { completeness, accuracy, interpretability, availability, } \\
\text { timeliness, price, objectivity, latency, and response time of } \\
\text { information }\end{array}$ \\
\hline Information Privacy & $\begin{array}{l}\text { Refers to sharing transactions with supply chain partners } \\
\text { openly, yet confidential, immutable, and secured manner }\end{array}$ \\
\hline Information Communication & $\begin{array}{l}\text { Refers to connectivity and willingness to share } \\
\text { information among supply chain partners to optimize } \\
\text { supply chain coordination }\end{array}$ \\
\hline Supply chain integration & $\begin{array}{l}\text { Refers to integrating people, processes and products of the } \\
\text { supply chain using modern technologies }\end{array}$ \\
\hline Compatibility and Interoperability & $\begin{array}{l}\text { Refers to the standardization of information, processes } \\
\text { and practices in supply chain operations across the supply } \\
\text { chain network }\end{array}$ \\
\hline Agility & $\begin{array}{l}\text { Refers to supply chain response to changing and } \\
\text { unpredictable environmental conditions }\end{array}$ \\
\hline Traceability & $\begin{array}{l}\text { Refers tracking of information flow and physical } \\
\text { movement of goods between supply chain partners }\end{array}$ \\
\hline Financing & $\begin{array}{l}\text { Refers to type of financial transactions used by firm with } \\
\text { their supplier }\end{array}$ \\
\hline $\begin{array}{l}\text { Refers to auditing and risk management to reduce supply } \\
\text { chain vulnerabilities }\end{array}$ \\
\hline
\end{tabular}

\section{Research Methodology}

This empirical study aims to quantitatively assess how ICT adoption benefits overall retail supply chain performance. The study also intends to identify the key functional elements based on their importance for ICT adoption to optimize overall retail supply chain performance. This study considers a multi-echelon downstream supply chain, as depicted in Figure 1.

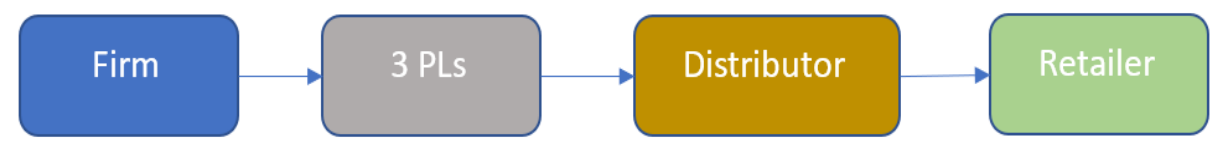

Figure 1. Multi-Echelon downstream supply chain.

Finding the important functional elements of the retail supply chain for ICT adoption to optimize the overall retail supply chain performance is a typical feature engineering problem. In feature engineering, domain knowledge is used to extract and score features from raw data based on their relevance to the prediction of a dependent variable using data mining techniques. These scores are then used to rank features based on their relevance to prediction or dependent variables. Figure 2 represents the end-to-end feature engineering process.

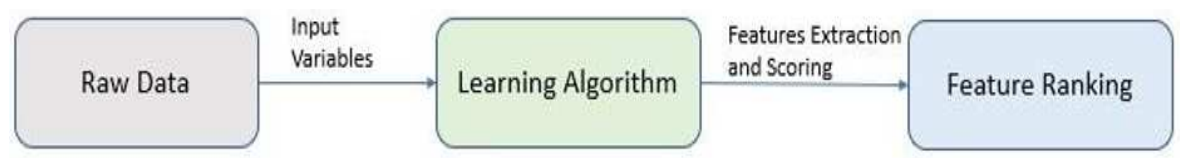

Figure 2. End-to-end feature engineering process.

The research methodology for this study comprises two steps, which are discussed below. 


\subsection{Selection of Data Collection Method}

We designed a questionnaire to collect empirical data required for this study and used Google Forms as a tool to prepare and share the questionnaire online. The questionnaire consists of a mix of dichotomous questions with comment boxes and uses a five-point Likert scale. This kind of data collection method allows individuals to express how much they agree or disagree with the relevance of each performance indicator in the context of the adoption of ICT for retail supply chain performance. The Likert scale items feature values such as " $1=$ Strongly Disagree" and " $5=$ Strongly Agree".

For data collection, we approached supply chain practitioners by joining various supply chain groups on LinkedIn. We used a keyword-based search to identify the profiles of practitioners who have experience in the retail industry. We searched Popular Linkedin supply chain groups such as Industry Engineers in Supply Chain Management, Supply Chain and Logistics Management, Supply Chain Management-International, and CSCMP-Council of Supply Chain Management Professionals. This method helped us to obtain the participation of respondents from different geographies and demographics. We approached them by sending InMail LinkedIn messages and shared the online questionnaire link with them. In addition to this, we also invited a focus group of practitioners, techno-functional experts, and decision-makers from the retail industry through personal networking to participate in the survey. We shared the online questionnaire with them by email. This data collection method ensures that the data obtained represent the practitioners' views and experiences in the field of retail supply chains. Hence, it is more reliable and accurate.

\subsection{Selection of Feature Engineering Method}

In this study, the prediction or dependent variable is the retail supply chain performance. We treat each function element considered for predicting its impact on the dependent variable as a feature. In practice, there are various methods available for feature selection or ranking. Figure 3 provides a summary of a hierarchy of feature selection techniques.

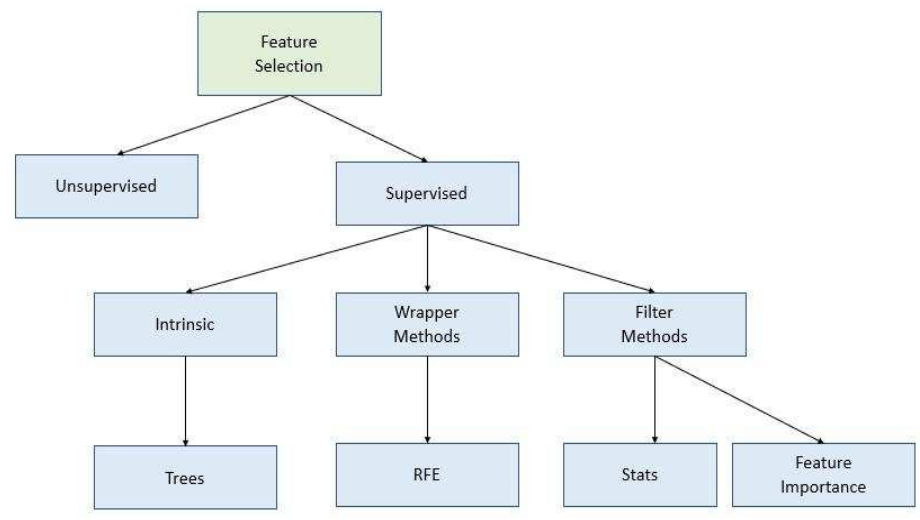

Figure 3. Feature engineering techniques.

The experimental data collected for assessing the importance of functional elements (independent variables) of the retail supply chain for ICT adoption to optimize overall supply chain performance is of ordered categorical data type due to its Likert scale nature. In reality, these ordered categories do not feature qualitative differences. Fundamentally, Likert scale items are discrete measurements about an underlying continuum. Hence, we used discrete categories that linked to the underlying continuum. Furthermore, the dependent or prediction variable is categorical (Yes/No) in nature. Thus for this study, classification algorithms are more suitable to solve the feature engineering problem. One research study recognizes that the Classification Tree or Random Forest algorithms for Likert-type experimental data are more appropriate, informative, and user-friendly. These methods offer many advantages and provide robust and accurate outcomes because they can analyze complex multifactorial interactions more effectively than traditional parametric 
tests [38]. These methods use recursive partitioning, bootstrapping, bagging, and crossvalidation to improve the accuracy of the result and handle a large number of predictors non-linearly [38].

We statistically tested all three classifier algorithms on the dataset used for empirical analysis in this study to choose the suitable algorithm. We employed the repeated stratified $\mathrm{k}$-fold cross-validation method with three repeats and 10 folds to calculate the statistical values for model accuracy and standard deviation and presented in Table 2.

Table 2. Statistical metrics of classifier algorithms.

\begin{tabular}{ccc}
\hline Classification Algorithm & Classification Accuracy & Standard Deviation \\
\hline Decision Tree & $90.08 \%$ & 0.05 \\
Random Forest Classifier & $94.1 \%$ & 0.02 \\
Extra Tree Classifier & $94.3 \%$ & 0.02 \\
\hline
\end{tabular}

The above comparison indicates that the Decision Tree classification algorithm features the lowest classification accuracy among the three algorithms. The extra Tree Classifier algorithm offers slightly higher accuracy than the Random Forest Classifier algorithm and is also computationally inexpensive. Hence, we chose the Extra Tree Classifier algorithm for this empirical study.

\section{Analysis and Discussion}

The analysis phase of the empirical study used the data collected through the online survey. We developed a feature engineering model for empirical analysis using the Python language as it features a rich set of libraries for data preparation and feature engineering. The algorithm of this model includes a pre-processing step as the first step for data preparation and uses Python's pandas functions. The second step in the model is to compute the participants' distribution and compute statistical metrics for assessing the benefit of ICT adoption on overall retail supply chain performance. The third step in the model algorithm is to execute the extra trees classifier functions from the Scikit-learn Python library for features ranking. The model is configured to assign value 100 to the property "n_estimators" of the extra tree classifier algorithm to estimate the ranking of the features with low entropy [39]. The last step in the algorithm is to plot the results using the Matplotlib Python library for better interpretation of the results.

Two-hundred and sixty-four people responded to the online questionnaire survey. The analysis of the output of the second step in the model interprets two different opinions on ICT adoption on retail supply chain performance. A total of $94 \%$ of the respondents believed that ICT adoption has a positive impact on retail supply chain performance. Surprisingly, $6 \%$ of the respondents believed that ICT adoption could adversely impact retail supply chain performance. For the purpose of discussion, we classified these respondents into two categories, as discussed below.

Category I: Represents the category of respondents who believe that ICT adoption has a positive impact on retail supply chain performance. Figure 4 illustrates the percentage distribution of category I respondents by retail industry type.

The data interpretation in Figure 4 indicates that the majority percentage of the category I respondents from all three retail industry types believe that ICT adoption benefits overall retail supply chain performance in the range of $0-35 \%$. There is a moderateto-low percentage of category I respondents from all three retail industry types who believe that the benefits of ICT adoption in the overall improvement of the retail supply chain performance range from $35-70 \%$. Furthermore, a small percentage of category I respondents from the FMCG and the food industries believe that ICT adoption significantly benefits overall retail supply chain performance. 


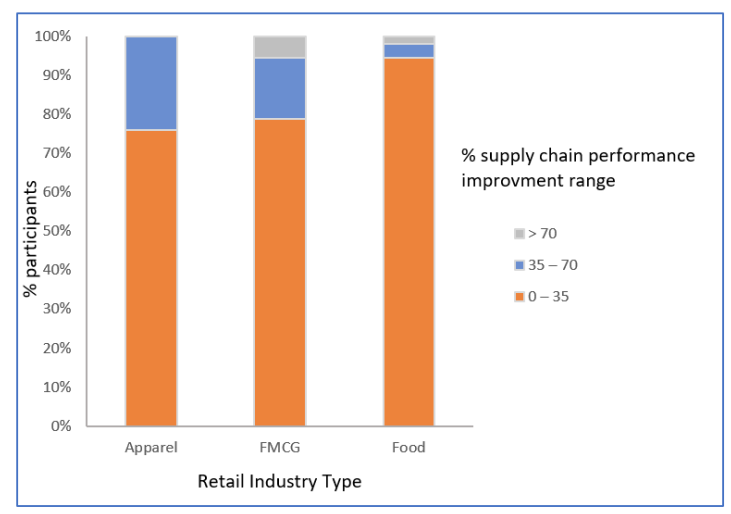

Figure 4. Percentage distribution of category I respondents by retail industry type.

The category I respondents from the food industry believe that the automation of the food processing chain and the centralized real-time monitoring of processing facilities using IoT and AI-based technologies help to improve food safety and quality and reduce wastage in different facilities. The automation of tasks for placing orders, dispatching, and billing reduces human error. The AI-driven automated food processing chain also allows the respondents to maintain low inventory levels and shorter lead times. The adoption of $\mathrm{AI}$ in food delivery services enables the respondents to provide personalized recommendations of food recipes and restaurants, resulting in enhanced customer satisfaction and maximized sales.

Category I respondents from the apparel industry emphasize that a combination of AI and 3D modeling technology allows retailers to offer digital samples to the customer and then place the order with the manufacturer as per customer preferences. Thus, retailers do not need to maintain a shelf inventory. Manufacturers also benefit from faster and more effective decisions, reduced fabric waste, and a smaller carbon footprint. With AIenabled technology, apparel firms set up virtual showrooms for their customers and allow their customers to place orders directly. The firms then deliver the apparel directly to the customers' doorsteps through local virtual retailers, thus eliminating the need to maintain physical showrooms in different locations.

According to the category I respondents from the FMCG industry, the ICT-enabled integration of distributed management software (DMS), field force tracking apps, and order processing apps allows them to track sales from siloed distributors. Retailers also benefit from the ability to place and track orders through mobile applications. They are also able to run targeted schemes and monitor their effectiveness. Cloud-based distributor intelligence solutions provide secured connectivity for the integration of system databases of supply chain partners to quickly obtain insights into the inventory levels of individual distributors. These insights help decision makers to determine the average stock replenishment duration of each distributor, ideal stocking levels based on sales patterns, and knowledge about which SKU performs in different regions, top-performing distributors, areas, and SKUs. Fitting AI-enabled recommendation engines with distributor intelligence systems allows them to create personalized incentive solutions for top-performing distributors to promote sales.

Thus, from the perspective of the respondents from category I, ICT adoption seamlessly connects the functional elements of the end-to-end retail supply chain to efficiently manage the four main pillars of the supply chain business. These four pillars are planning, procurement, manufacturing, and logistics. Therefore, these respondents believe that ICT plays a significant role in making the retail supply chain more efficient and robust for disruptions.

Table 3 represents the statistical metrics calculated to determine the \% improvement in retail supply chain performance based on the responses of the category I respondents. 
Table 3. Statistical metrics for \% improvement in retail supply chain performance.

\begin{tabular}{cc}
\hline Statistical Parameter & Value \\
\hline Mean & 25.4518 \\
Median & 22.0076 \\
Mode & 15.1191 \\
Standard Deviation & 16.269 \\
Coefficient of Variation $(\mathrm{CV})$ & 0.6392 \\
\hline
\end{tabular}

The data analysis presented in Table 3 implies that the category I respondents believe that ICT adoption would provide an average $25 \%$ improvement in overall retail supply chain performance. The mode value in the above table represents the majority of the category I respondents, who believe that the benefit of ICT adoption on overall retail supply chain performance would be $15 \%$. With a standard deviation of 16.269 , the improvement of overall retail supply chain performance through the adoption of ICT would be in the range of $9-41 \%$. The value of the coefficient of variation is less than 1 , indicating the low variance in the dataset used in this study.

Category II: Represents the category of respondents who believe that ICT adoption has a negative impact on retail supply chain performance. Figure 5 illustrates the percentage distribution of category II respondents by retail industry type.

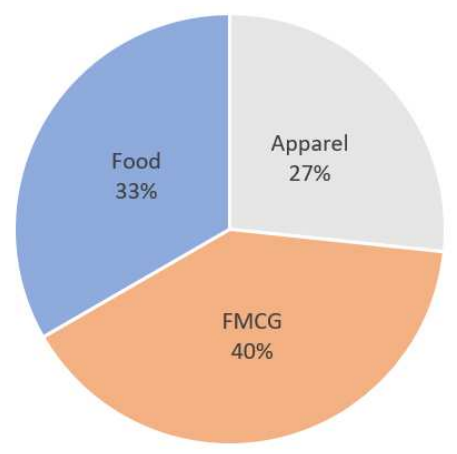

Figure 5. Percentage distribution of category II respondents by retail industry type.

The data analysis in Figure 5 shows that the category II respondents from the FMCG industry firmly believe that the mere adoption of ICT may not help to optimize retail supply chain performance. The category II respondents from the Food and Apparel industry also moderately support the perspective of the respondents from FMCG industry. This analysis clearly supports the literature review's finding that the willingness to collaborate among supply chain members is equally important to maximize the operational performance of the retail supply chain.

The category II respondents believe that the investment in modern technologies leads to a higher overall cost for business for supply chain partners and thus offsets the benefit of using ICT to improve supply chain coordination. This opinion could be valid for microsupply chain partners such as individual retail stores. The rationale for this is that the volume of products that these types of businesses sell is limited, so their overall earnings may not be high enough to accommodate the investment in technology. Furthermore, enforcing strict governance practices through ICT could create mistrust among supply chain partners, unsettling long-running relationships with firms.

Figure 6 represents the output of the last step of the feature engineering model to provide a visual comparison of the importance of different functional elements of the retail supply chain for ICT adoption for optimal supply chain performance. 


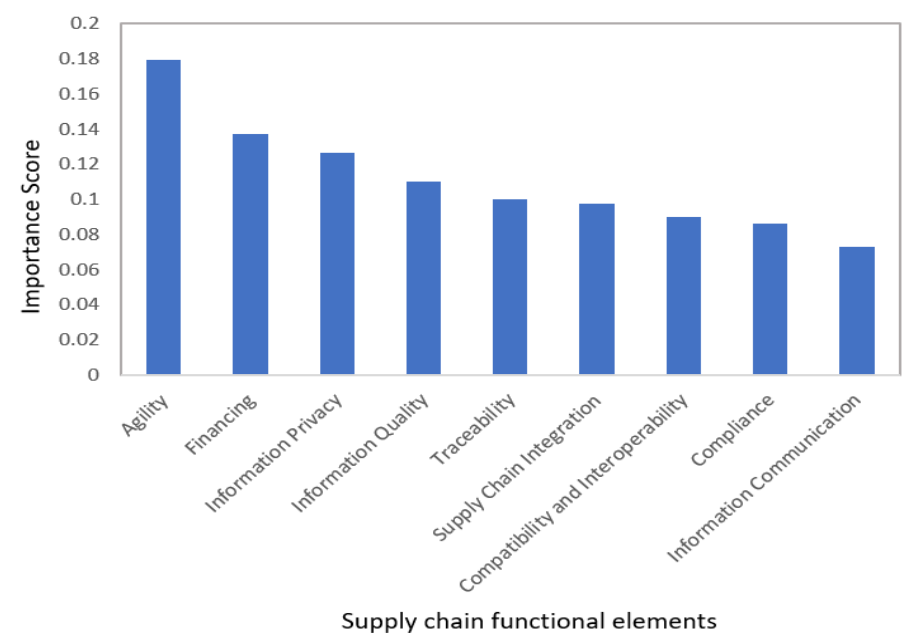

Figure 6. Supply chain functional elements based on their importance for ICT adoption.

After careful analysis of the data in Figure 6, we inferred that from the category 1 respondents' perspective, ICT adoption introduces agility into supply chains and would therefore be a top priority for firms to improve retail supply chain performance. ICT-driven supply chain agility creates better synergies among supply chain partners and better visibility and control over inventories, leading to the optimum operational performance of the supply chain network. However, supply chain agility requires strong collaboration between supply chain members through real-time information sharing. Hence, information communication becomes a crucial element in the introduction of agility into the supply chain. Surprisingly, this study found that the respondents attributed the lowest level of importance to information communication. Thus, we inferred that information communication should be considered as an inherent element of supply chain agility for assessing the adoption of ICT for retail supply chain performance.

ICT adoption in functional elements, such as information privacy and financing, also received high importance scores on questions about improving retail supply chain performance. The use of ICT in supply chains enables the prompt detection of breaches in data confidentiality during data exchange and prompts proactive action to eliminate the violation of integrity in supply chain businesses. This creates confidence among supply chain participants, resulting in improved supply chain coordination. The use of ICT in supply chain financing reduces payment delays, administrative overheads, and corruption risks, ensuring timely payment to supply chain partners. Thus, it helps to boost trust and morale among supply chain partners, which encourages them to make extra efforts to improve the business.

The importance scores obtained for information quality, traceability, and supply chain integration reveal that ICT adoption in these functional elements could moderate retail supply chain performance. The adoption of ICT ensures the exchange of complete and contextual information, helping supply chain partners to make optimal decisions and to act promptly. Furthermore, ICT adoption aids in changing supply chain participants' perspectives from cost-based considerations to value-based considerations and thus enables them to focus on traceability aspects in order to improve supply chain performance. Investment in modern technologies makes supply chain integration more robust, resulting in a positive impact on supply chain performance.

Surprisingly, the effect of ICT adoption on compatibility and interoperability, and compliance, received low importance scores. However, the standardization of supply chain processes and practices and the creation of unified semantics for the interpretation of business information through the use of modern technologies improves compatibility and interoperability, leading to a value-based supply chain. Furthermore, the use of ICT helps to make supply chains more compliant to trade regulations and helps supply chain 
businesses to avoid costly violations, which itself helps to preserve the firms' reputations in the global market.

\section{Validation of Results}

We conducted semi-structured interviews to test the results of the empirical study qualitatively. We interviewed two supply chain experts from a global apparel company selling luxury fashion products. Due to the lockdown, we conducted the interviews using the Zoom digital platform.

During the interview, we apprised the participants of the rationale behind carrying out this empirical study. We asked semi-structured questions to obtain their perspectives on the adoption of ICT and its effects on the different functional elements identified by the empirical study. We also asked them to share their real-world experiences on how ICT adoption has improved their supply chain performance. We recorded each interview, which lasted approximately one hour. The objective of this exercise was to ensure triangulation and cross-checking.

According to the supply chain experts, ICT plays a significant role in improving the overall performance of the retail supply chain. The supply chain experts also believe that supply chain integration, information communication, and compatibility and interoperability are intrinsic constituents to introduce agility into the supply chain. Hence, we should treat these constituents as a single, coherent, functional element of the supply chain under the heading, Supply Chain Agility. To support their belief, the experts emphasized the leveraging of next-generation SaaS platforms that natively offer cross-platform integration capabilities and provide standard semantics for enterprise business information. No-code or low-code customizations on unified data semantics enable firms to generalize business rules and processes across the supply chain ecosystem and deploy supply chain processes more quickly into practice. Furthermore, these platforms allow firms to create a digital network of internal stakeholders and external partners and provide standardized protocols to share information among them efficiently. Supply chain experts observe an improvement of approximately $35-40 \%$ in agility in their supply chain using these platforms.

From the supply chain experts' perspective, traceability is a critical functional element of supply chains. Traceability reduces losses due to theft or misplacement of goods and thus creates a value-based proposition for the supply chain. Intelligent track-and-trace systems connect the dots in supply chains to track the movement of goods from source to consumer. These systems reduce the risk of mislabeling and enable rapid traceability analysis to handle crises such as recalls and counterfeit products, thereby helping retail firms to protect their brand. IoT and blockchain-enabled Track-and-Trace systems provide end-to-end supply chain visibility and offer opportunities for retailers to adopt progressive procurement strategies to mitigate the risk of changing customer demands. The progressive procurement approach offers triple benefits for the supply chain in terms of increase in retailer's profit, minimize losses due to expiry of product's shelf life, and healthy supplier relationships.

The supply chain experts also stressed that incomplete and ambiguous data cause poor business decisions and inefficiencies in supply chain operations. Hence, information quality is a critical element in the efficient coordination of supply chains. AI-ML-based digital supply chain systems provide good-quality information and minimize the Bullwhip effect by accurately predicting inventory needs at each stage of multi-echelon supply chains. A reduction in the Bullwhip effect decreases the revenue losses associated with the incorrect determination of inventory needs to manage material flow during sudden spikes in customer demand.

The supply chain experts indicated that the digitalization of supply chain financing creates efficiencies in procurement processes and strengthens compliance and control among supply chain partners, contracts, regulations, and accounts payable. Digital systems help to reduce manual paperwork in the procurement process and ensure seamless receipt and reconciliation. E-payment systems integrate invoice approval and payment workflows to reduce the cycle time of payment settlement processes. Thus, ICT adoption 
in financing enhances financial flow within supply chains and builds trusted relationships with B2B partners.

Information privacy involves the proper handling of data, focusing on compliance with data protection regulations. Hence, the supply chain experts highlighted that compliance is an inherent part of information privacy. Modern ERP and Control Tower solutions securely share data across different segments of the supply chain by using industrystandard encryption methods, offer granular-level access control to protect data privacy and minimize compliance risks during information sharing. However, the supply chain experts indicated that the supply chain as a whole is secured when all entities throughout the supply chain are engaged and use effective and coordinated security measures to ensure the integrity of supply chain information.

The supply chain experts recommended the key functional elements of the retail supply chain to focus on for ICT adoption to obtain maximum performance benefits. Table 4 lists these functional elements based on their relevance for ICT adoption to maximize retail supply chain performance.

Table 4. List of key functional elements for ICT adoption to optimize retail supply chain performance.

\begin{tabular}{ccc}
\hline Functional Element & Merged Elements & Ranking \\
\hline Agility & Information Communication, Compatibility and & 1 \\
Traceability & Interoperability, Supply Chain Integration & 2 \\
Information Quality & - & 3 \\
Financing & - & 4 \\
Information Privacy & Compliance & 5 \\
\hline
\end{tabular}

The supply chain experts also suggested that mere investment in digital systems does not help to improve supply chain performance. Instead, firms and strategic supply chain partners should encourage basic or small retailers to participate in their digital supply chain journey by adopting Software-as-a-Service based digital platforms, with minimum subscription costs. This approach will help firms to create inclusive supply chain strategies for supply chain sustainability and efficiency.

\section{Conclusions}

This study concludes that adopting ICT in the downstream part of the multi-echelon supply chain offers a performance improvement in the range of $9-41 \%$ for the retail industry. However, this benefit could be different for the upstream part of the multi-echelon supply chain; to determine whether this is the case, future research is required. Hence, we do not claim the applicability of this study across the entirety of the multi-echelon supply chain. However, supply chain practitioners can use the outcome of this study as a guideline to develop an appropriate ICT adoption strategy in their supply chain to achieve their desired performance.

This study also concludes that merely investing in modern technologies does not improve supply chain performance. Improvement requires supply chain participants' willingness to share accurate and complete information and raise incidents in the supply chain process quickly to make the supply chain more collaborative and efficient.

The outcome of this study suggests that agility, traceability, information quality, financing, and information privacy are the key functional elements for to the adoption of ICT in order to optimize the retail supply chain performance.

The feature engineering model used in this empirical study to prioritize the functional elements of the retail supply chain based on their importance for ICT adoption is reasonably accurate. The error in ranking accuracy predicted by the model could be due to the method used for the data collection. The online survey respondents were supply chain practitioners from broader retail industry segments such as the apparel, food, and FMCG industries. However, the supply chain experts interviewed to validate the outcome of the feature 
engineering model were from an apparel industry selling luxury fashion brands. Retail companies selling luxury brands would have different priorities in their adoption of ICT than those selling non-luxury brands. Furthermore, the preferences of these functional elements for ICT adoption could depend upon the needs of different business types within the retail industry. This could lead to some deviations in the outcome of the model. Thus, the general applicability of this model across different retail industry types may require further investigation in future research.

Author Contributions: Conceptualization, K.S. and A.B.; Formal analysis, K.S.; Investigation, K.S.; Methodology, K.S. and S.K.; Resources, K.K.; Supervision, S.K., K.K. and C.P.; Validation, S.K.; Writing—original draft, K.S. and A.B.; Writing—review \& editing, A.B., S.K. and C.P. All authors have read and agreed to the published version of the manuscript.

Funding: This research received no external funding.

Institutional Review Board Statement: Not applicable.

Informed Consent Statement: Not applicable.

Data Availability Statement: Not applicable.

Acknowledgments: We would like to express our gratitude to Supply chain experts, Supreet Singh Nanda, Principal Solution Advisor from Ralph Lauren and Ashwin Deshpande from Infosys working as Industry Solution Architect for Adidas for providing their valuable views and comments based on their practitioner experiences to enrich the outcome of research study. We wish to extend our special thanks to supply chain experts and technologists who had participated in an online survey and provided their unbiased answers to questionnaire.

Conflicts of Interest: The authors declare no conflict of interest.

\section{References}

1. Chowdhury, P.; Paul, S.K.; Kaisar, S.; Moktadir, M.A. COVID-19 pandemic related supply chain studies: A systematic review. Transp. Res. Part E Logist. Transp. Rev. 2021, 148, 102271. [CrossRef]

2. SAP Leading the Fast-Growing SCM Market with $26 \%$ Share. Available online: https://www.forbes.com/sites/louiscolumbus / 2018/07/28/sap-leading-the-fast-growing-scm-market-with-26-share/?sh=34ac5f6170df (accessed on 17 May 2021).

3. Acar, A.Z.; Uzunlar, M.B. The effects of process development and information technology on time-based supply chain performance. Procedia-Soc. Behav. Sci. 2014, 150, 744-753. [CrossRef]

4. Messina, D.; Barros, A.C.; Soares, A.L. An Information Management Perspective of Supplier Selection Process in Manufacturing Networks. In Proceedings of the 17th Working Conference on Virtual Enterprises, PRO-VE 2016, Porto, Portugal, 3-5 October 2016; Springer: Cham, Switzerland, 2016; pp. 178-188.

5. Colin, M.; Galindo, R.; Hernández, O. Information and communication technology as a key strategy for efficient supply chain management in manufacturing SMEs. Procedia Comput. Sci. 2015, 55, 833-842. [CrossRef]

6. Apiyo, R.O.; Kiarie, D.M. Role of ICT tools in supply chain performance. Int. J. Supply Chain Manag. $2018,3,17-26$.

7. Calatayud, A.; Mangan, J.; Christopher, M. The self-thinking supply chain. Supply Chain Manag. Int. J. 2019, 24, 22-38. [CrossRef]

8. Fawcett, S.E.; Osterhaus, P.; Magnan, G.M.; Brau, J.C.; McCarter, M.W. Information sharing and supply chain performance: The role of connectivity and willingness. Supply Chain Manag. Int. J. 2007, 12, 358-368. [CrossRef]

9. Lin, T.H.; Lin, I.C. Factors for information technology acceptance willingness and adoption in logistics industry from supply chain perspectives. Int. J. Electron. Bus. Manag. 2014, 12, 167.

10. Hendy, T.; Resdiansyah, R.; Johanes, F.A.; Rustono, F.M. Exploring The Role of ICT Readiness and Information Sharing On Supply Chain Performance in Coronavirus Disruptions. Technol. Rep. Kansai Univ. 2020, 62, 2581-2588.

11. Nath, T.; Standing, C. Drivers of Information Technology Use in the Supply Chain. J. Syst. Inf. Technol. 2010, 12, 70-84. [CrossRef]

12. Li, S.; Lin, B. Accessing information sharing and information quality in supply chain management. Decis. Support Syst. 2006, 42, 1641-1656. [CrossRef]

13. Lee, C.; Ha, B.C. Interactional Justice, Informational Quality, and Sustainable Supply Chain Management: A Comparison of Domestic and Multinational Pharmaceutical Companies. Sustainability 2021, 13, 998. [CrossRef]

14. Tan, K.H.; Wong, W.P.; Chung, L. Information and knowledge leakage in supply chain. Inf. Syst. Front. 2016, 18, 621-638. [CrossRef]

15. Wu, H.; Li, Z.; King, B.; Ben Miled, Z.; Wassick, J.; Tazelaar, J. A distributed ledger for supply chain physical distribution visibility. Information 2017, 8, 137. [CrossRef]

16. Lotfi, Z.; Mukhtar, M.; Sahran, S.; Zadeh, A.T. Information sharing in supply chain management. Procedia Technol. 2013, 11, 298-304. [CrossRef] 
17. Bader, L.; Pennekamp, J.; Matzutt, R.; Hedderich, D.; Kowalski, M.; Lücken, V.; Wehrle, K. Blockchain-based privacy preservation for supply chains supporting lightweight multihop information accountability. Inf. Process. Manag. 2021, 58, 102529. [CrossRef]

18. Surjandari, I.; Yusuf, H.; Laoh, E.; Maulida, R. Designing a Permissioned Blockchain Network for the Halal Industry using Hyperledger Fabric with multiple channels and the raft consensus mechanism. J. Big Data 2021, 8, 10. [CrossRef]

19. Rajaguru, R.; Matanda, M.J. Role of compatibility and supply chain process integration in facilitating supply chain capabilities and organizational performance. Supply Chain Manag. 2019, 24, 301-316. [CrossRef]

20. Pala, M.; Edum-Fotwe, F.; Ruikar, K.; Doughty, N.; Peters, C. Contractor practices for managing extended supply chain tiers. Supply Chain Manag. Int. J. 2014, 19, 31-45. [CrossRef]

21. Agarwal, A.; Shankar, R.; Tiwari, M.K. Modeling agility of supply chain. Ind. Mark. Manag. 2007, 36, 443-457. [CrossRef]

22. Swafford, P.M.; Ghosh, S.; Murthy, N. Achieving supply chain agility through IT integration and flexibility. Int. J. Prod. Econ. 2008, 116, 288-297. [CrossRef]

23. Khan, H.; Wisner, J.D. Supply chain integration, learning, and agility: Effects on performance. J. Oper. Supply Chain Manag. 2019, 12, 14-23. [CrossRef]

24. Kim, S.; Park, S.; Noh, H.; Kim, S.C. Impact of ICT Capability on Real Time Enterprise Capability and Supply Chain Performance. J. Soc. Korea Ind. Syst. Eng. 2020, 43, 110-122. [CrossRef]

25. García-Alcaraz, J.L.; Maldonado-Macías, A.A.; Alor-Hernández, G.; Sánchez-Ramírez, C. The impact of information and communication technologies (ICT) on agility, operating, and economical performance of supply chain. Adv. Prod. Eng. Manag. 2017, 12, 29-40. [CrossRef]

26. Kamble, S.S.; Gunasekaran, A.; Gawankar, S.A. Achieving sustainable performance in a data-driven agriculture supply chain: A review for research and applications. Int. J. Prod. Econ. 2020, 219, 179-194. [CrossRef]

27. Tripathy, S.; Aich, S.; Chakraborty, A.; Lee, G.M. Information technology is an enabling factor affecting supply chain performance in Indian SMEs: A structural equation modelling approach. J. Model. Manag. 2016, 11, 269-287. [CrossRef]

28. MahbubulHye, A.K.; Miraz, M.H.; Sharif, K.I.M.; Hassan, M.G. Factors affecting on elogistic: Mediating role of ICT \& technology integration in retail supply chain in Malaysia. Test Eng. Manag. 2020, 82, 3234-3243.

29. Shee, H.; Miah, S.J.; Fairfield, L.; Pujawan, N. The impact of cloud-enabled process integration on supply chain performance and firm sustainability: The moderating role of top management. Supply Chain Manag. 2018, 23, 500-517. [CrossRef]

30. Saurabh, S.; Dey, K. Blockchain technology adoption, architecture, and sustainable agrifood supply chains. J. Clean. Prod. 2020, 24, 124731. [CrossRef]

31. Wu, Y.; Wang, Y.; Xu, X.; Chen, X. Collect payment early, late, or through a third party's reverse factoring in a supply chain. Int. J. Prod. Econ. 2019, 218, 245259. [CrossRef]

32. Thogori, M.; Gathenya, J.; Kihoro, J.M. Moderating effect of ICT on supply chain financial flow risk and performance of manufacturing firms in Kenya. Int. J. Acad. Res. Bus. Soc. Sci. 2017, 273-293. [CrossRef]

33. Nadeem, S.; Alvi, A.K.; Iqbal, J. Performance indicators of e-logistic system with mediating role of Information and Communication Technology (ICT). J. Appl. Econ. Bus. Res. 2018, 8, 217-228.

34. Nikoofal, M.E.; Gümüş, M. Value of audit for supply chains with hidden action and information. Eur. J. Oper. Res. 2020, 285, 902-9215. [CrossRef]

35. Castka, P.; Searcy, C.; Mohr, J. Technology-enhanced auditing: Improving veracity and timeliness in social and environmental audits of supply chains. J. Clean. Prod. 2020, 258, 120773. [CrossRef]

36. Mauermair, J. Compliance and Supply Chain Safety. In Supply Chain Safety Management; Springer: Berlin/Heidelberg, Germany, 2013; pp. 299-308.

37. Rejeb, A.; Keogh, J.G.; Treiblmaier, H. Leveraging the internet of things and blockchain technology in supply chain management. Future Internet 2019, 11, 161. [CrossRef]

38. Endresen, A.; Janda, L.A. Five statistical models for Likert-type experimental data on acceptability judgments. J. Res. Des. Stat. Linguist. Commun. Sci. 2016, 3, 2017-2050. [CrossRef]

39. Decision Trees: Gini vs. Entropy. Available online: https://quantdare.com/decision-trees-gini-vs-entropy (accessed on 25 June 2021). 